\title{
Aplicação de redes neurais artificiais para previsão de enchentes no Rio Itajaí-Açu em Blumenau, SC, Brasil
}

As redes neurais artificiais (RNA) têm sido utilizadas com sucesso em previsões de variáveis baseadas em acontecimentos anteriores, porém, escassos são os estudos sobre a aplicação dessa solução à previsão de níveis de rio em eventos de enchentes. Este estudo teve como objetivo avaliar a aplicação de RNA para previsão em curto prazo dos níveis do rio Itajaí-Açu no município de Blumenau, Santa Catarina, Brasil. O município foi escolhido como área de estudo por seu extenso histórico de inundações. Utilizou-se para o treinamento das redes dados de chuva e de nível do rio das estações telemétricas do Sistema Nacional de Informações sobre Recursos Hídricos (SNIRH) da Agência Nacional de Águas (ANA) localizadas na bacia hidrográfica do rio ItajaíAçu. Ambos dados apresentam frequência de $15 \mathrm{~min}$. Foram selecionados 7 eventos hidrológicos de alerta registrados pela estação limnimétrica instalada no município de Blumenau. Os Açu. Ambos dados apresentam frequência de $15 \mathrm{~min}$. Foram selecionados 7 eventos hidrologicos de alerta registrados pela estaçãólimnimetrica instalada no municipio de Blumenau. Os dados foram coletados e reunidos de acordo com sua localização e tipo, e foram escalados à mesma unidade de medida: $\mathrm{cm}$ para níveis e mm para dados de precipitação. Foram utilizados dois tipos de redes: Long Short Term Memory (LSTM) e Multi Layer Perceptron (MLP). Para avaliação de desempenho dos modelos, utilizou-se os seguintes parâmetros: coeficiente de
determinação (R2), o Coeficiente de Eficiência de Nash-Sutcliffe (NSE), a Raiz do Erro Quadrático Médio (RMSE), Erro Quadrático Médio (MSE), o Erro Médio Absoluto (MAE) e a Média Percentual Absoluta do Erro (MAPE). Para o modelo com melhor desempenho - modelo LSTM com horizonte de previsão de $6 \mathrm{~h}-$ obteve-se: $\mathrm{R2}=0,996594 ; \mathrm{NSE}=0,9995548 ; \mathrm{RMSE}=7,72$ $\mathrm{cm} ; \mathrm{MSE}=59,65 \mathrm{~cm} ; \mathrm{MAE}=4,82 \mathrm{~cm}$; MAPE = 1,89\%; e MSE val. = 0,000035. O estudo evidenciou que o modelo LSTM, com simples pré-processamento, é capaz de prever o nível do ItajaAçu durante eventos extremos de cheia, com alta precisão, apresentando resultados melhores em comparação com o modelo MLP. Este estudo apresenta uma proposta de solução de modelo de previsão de níveis viável, passível de aplicação como ferramenta de previsão em tempo real para a área de estudo. Este trabalho contribui para o desenvolvimento de sistemas de apoio à gestão de recursos hídricos e para mitigação dos impactos provocados por desastres, abrangendo os âmbitos social, econômico e ambiental.

\section{Application of neural networks for flood forecasting in the Itajaí-Açu River in Blumenau, SC, Brazil}

\begin{abstract}
Artificial neural networks (ANN) have been used successfully in predicting variables based on previous events, however, there are few studies on the application of this solution to river levels forecasting in flood events. This study aimed to evaluate the application of ANN to the levels forecasting of the Itajai-Açu river in the short term in the municipality of Blumenau, Sant Catarina, Brazil. Blumenau was chosen as a study area for its extensive history of flooding. Rain and river level data from the telemetric stations located in the hydrographic basin of the ItajaíAçu river of the Brazilian National Water Resources Information System (SNIRH) - National Water Agency (ANA) - were used to train the neural networks. Both data have a frequency of 15 Açu river of the Brazilian National Water Resources Information System (SNIRH) - National Water Agency (ANA) - were used to train the neural networks. Both data have a frequency of 15
min. 7 hydrological alert events registered by the limnimetric station installed in the municipality of Blumenau were selected. The data were collected and gathered according to their location and type, and were scaled to the same unit of measurement: $\mathrm{cm}$ for levels and $\mathrm{mm}$ for precipitation. Two types of neural networks were used: Long Short-Term Memory (LSTM) and MultiLayer Perceptron (MLP). To evaluate the performance of the neural networks, the following parameters were used: coefficient of determination (R2), Nash-Sutcliffe Efficiency Coefficient (NSE), Root-mean Square Error (RMSE), Mean Square Error (MSE), the Mean Absolute Error (MAE) and the Mean Absolute Percentage Error (MAPE). The model with the best performance LSTM model with $6 \mathrm{~h}$ forecast horizon - presented: R2 $=0.996594 ; \mathrm{NSE}=0.9995548 ; \mathrm{RMSE}=7.72 \mathrm{~cm} ; \mathrm{MSE}=59.65 \mathrm{~cm} ; \mathrm{MAE}=4.82 \mathrm{~cm} ; \mathrm{MAPE}=1.89 \% ;$ and MSE val. $=0.000035$. The study showed that the ISTM model, with simple preprocessing is cap study contributes to the development of support systems for the management of water resources and to mitigate the impacts caused by disasters, covering social, economic and environmental spheres.
\end{abstract}

Keywords: Hydrology; Level forecasting; Artificial neural networks (ANN); Deep learning.

Topic: Tecnologia, Modelagem e Geoprocessamento

Received: 02/04/2021

Approved: 29/04/2021

Reviewed anonymously in the process of blind peer.

Gabriel Barreto Alberton (iD

Fundação Universidade Regional de Blumenau, Brasil

http://lattes.cnpq.br/1274141336139009

http://orcid.org/0000-0002-6469-2793

gabrielalberton@hotmail.com

Dirceu Luis Severo (iD

Fundação Universidade Regional de Blumenau, Brasil http://lattes.cnpq.br/7916690151293911

http://orcid.org/0000-0001-5701-484X

severo@furb.br

Mateus Nascimento Vieira de Melo (iD)

Fundação Universidade Regional de Blumenau, Brasi

http://lattes.cnpq.br/7021645186224738

http://orcid.org/0000-0002-8166-8621

mateusnvm@gmail.com

\author{
Hélio Potelicki ito \\ Fundação Universidade Regional de Blumenau, Brasil \\ http://lattes.cnpq.br/6985909504878433 \\ http://orcid.org/0000-0003-2545-0043 \\ helio.p2000@hotmail.com \\ Andreza Sartori (ii) \\ Fundação Universidade Regional de Blumenau, Brasil \\ http://lattes.cnpq.br/3277020795353298 \\ http://orcid.org/0000-0002-3982-8767 \\ asartori@furb.br
}

Referencing this:

ALBERTON, G. B.; SEVERO, D. L.; MELO, M. N. V.; POTELICKI, H. SARTORI, A.. Aplicação de redes neurais artificiais para previsão de enchentes no Rio Itajaí-Açu em Blumenau, SC, Brasil. Revista Ibero Americana de Ciências Ambientais, v.12, n.4, p.686-696, 2021. DOI: http://doi.org/10.6008/CBPC2179-6858.2021.004.0053 


\section{INTRODUÇÃO}

Enchentes causam grande devastação, perdas socioeconômicas e de vidas humanas. De acordo com Jha et al. (2012), a ocorrência de inundações é o mais frequente dentre todos os desastres naturais. O Brasil aparece entre os 15 países do mundo em população exposta ao risco de inundação de rios. Na América Latina e Caribe, entre os anos 2000 e 2019, 12 enchentes trouxerem prejuízos próximos a US\$ 1 bilhão. No Brasil, 0,9\% dos 190,7 milhões de habitantes correram o risco de ser afetados por cheias (UN OCHA, 2019). Dentre as regiões do Brasil, a região Sul detém o maior número de eventos desta natureza por área. 0 estado de Santa Catarina se destaca no histórico de sinistros hidrológicos (CEPED et al., 2013). A bacia hidrográfica do rio Itajaí-Açu é uma das grandes responsáveis pelo elevado número de desastres no estado. Apenas no município de Blumenau, até o ano de 2011, foram registrados 77 eventos de extravasamento do rio (CORDERO et al., 2013).

A maior parte da rede brasileira de estações de monitoramento hidrológico dispõe somente de dados fluviométricos e pluviométricos (ANA, 2015). A carência de dados hidrológicos dificulta a adoção de metodologias de previsão de cheias que utilizam modelos mais sofisticados nos quais, em geral, há necessidade de calibração de grande número de parâmetros.

O Centro de Operação do Sistema de Alerta (CEOPS) é responsável pelo monitoramento da bacia hidrográfica do rio Itajaí-Açu. O CEOPS realiza projeções de nível do rio para diversos municípios, inclusive o de Blumenau, com antecedência de 6 e 8 horas. Os especialistas utilizam método empírico ajustado com base na experiência adquirida em eventos anteriores. Esse método ainda é adotado pela sua eficácia, porém, depende do conhecimento e experiência dos especialistas para cada previsão, o que dificulta a realização constante de previsões em tempo real. Não foram encontrados estudos com soluções efetivas à previsão em tempo real do nível para o município de Blumenau.

Redes Neurais Artificiais (RNA) têm sido atualmente apresentadas como uma alternativa aos métodos tradicionais para solução de problemas de previsão de séries temporais. Essa técnica dispensa dados hidrológicos mais detalhados, tais como fisiografia, estado e constituição do solo e umidade antecedente (CRUZ et al., 2010). Com baixo custo de implantação, esse método pode representar uma solução não só para Blumenau, mas para áreas carentes de sistemas de previsão e alerta em tempo real. Entretanto, poucos são os estudos envolvendo a aplicação de algoritmos de RNA a previsões de enchentes (HU et al., 2018).

Mosavi et al. (2018) realizaram uma revisão da utilização de aprendizado de máquina para previsão de inundações. Zhang et al. (2018) compararam o desempenho de diversas RNA para previsão, não de nível fluviométrico, mas de nível freático. Liang et al. (2018) utilizaram as redes para estabelecer um modelo preditor de níveis diários de água de um lago. Hu et al. (2018) utilizaram as redes para previsão de vazões em um rio.

Este estudo teve como objetivo avaliar a aplicação de RNA para previsão em curto prazo dos níveis do rio Itajaí-Açu no município de Blumenau, Santa Catarina, Brasil. Busca-se, assim, contribuir para a 
mitigação dos impactos sociais, ambientais e econômicos negativos provocados pelos eventos de enchentes.

\section{METODOLOGIA}

\section{Área de estudo}

O estudo foi desenvolvido na bacia hidrográfica do rio Itajaí-Açu (entre as coordenadas $26^{\circ} 41^{\prime} 54^{\prime \prime}$ e $27^{\circ} 41^{\prime} 02^{\prime \prime}$ de latitude sul e as coordenadas $48^{\circ} 39^{\prime} 39^{\prime \prime}$ e $50^{\circ} 07^{\prime} 07^{\prime \prime}$ de longitude oeste) (Erro! Fonte de referência não encontrada.). A bacia possui área de $14.381,1 \mathrm{~km}^{2}$ e perímetro de $648,3 \mathrm{~km}$. O percurso do rio Itajaí-Açu apresenta, aproximadamente, $200 \mathrm{~km}$ desde as cabeceiras até sua foz no Oceano Atlântico. Escolheu-se essa área de estudo devido a potencial base de dados históricos disponível, a frequência de eventos de enchentes e fatores que propiciam esta recorrência.

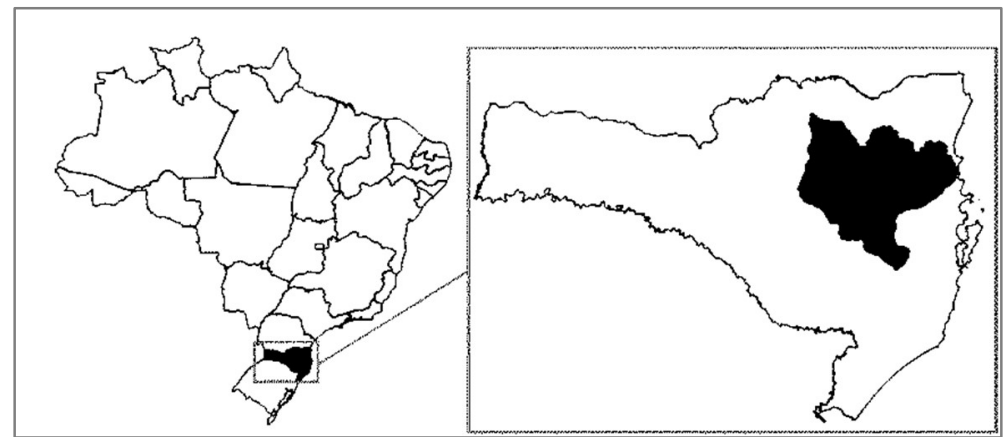

Figura 1: Localização da bacia hidrográfica do rio Itajaí-Açu, Santa Catarina, Brasil.

A densidade de drenagem da bacia hidrográfica é de $0,2 \mathrm{~km} / \mathrm{km}^{2}$ (GERBER et al., 2018). De acordo com Villela et al. (1975), esse índice pode variar de $0,5 \mathrm{~km} / \mathrm{km}^{2}$ em bacias com drenagem pobre a 3,5 km/ $\mathrm{km}^{2}$ ou mais em bacias bem drenadas, indicando, assim, que a bacia hidrográfica do estudo possui baixa capacidade de drenagem.

A altimetria da bacia hidrográfica varia de 1 m, no município de Itajaí, a 1736 m, no município de Alfredo Wagner. Castro (2003) explica que áreas com relevo acidentado favorecem o escoamento das águas, elevando a velocidade de descida, contribuindo para intensificação da torrente e ocorrência de danos. Esse fenômeno costuma surpreender por sua intensidade e menor previsibilidade, exigindo um monitoramento complexo. A bacia hidrográfica possui uma grande área de baixa altitude. Kron (2005) explica que essa característica favorece o acúmulo de água nessa região.

A área de estudo possui precipitação anual média de 1657,2 mm, com máxima de 2701,6 e mínima de 1110,7 mm. Na escala mensal, possui precipitação média de 138,8 mm, mínima de 1,0 mm e máxima de 1001,2 mm. De acordo com Gotardo et al. (2018), nota-se um menor volume de chuva durante o outono e o inverto, e maior volume durante na primavera e verão

A vazão média de monitoramento no exutório da bacia hidrográfica é de aproximadamente 420,0 $\mathrm{m}^{3} / \mathrm{s}$. Na maior parte do tempo, o rio tende a apresentar vazões abaixo da média, ocorrendo picos esporádicos que podem atingir mais de $3.000 \mathrm{~m}^{3} / \mathrm{s}$ (SCHETTINI, 2002). O tempo de resposta da bacia é inferior a 24 h. Porém, para Blumenau, em geral, apenas previsões com horizontes de $8 \mathrm{~h}$ ou inferiores, e que já 
levam em consideração valores de nível à montante, são confiáveis. Previsões com horizontes maiores devem ser ajustadas.

\section{Dados}

A disposição de grande quantidade de dados é necessária para o aprendizado profundo. As vantagens do aprendizado profundo aumentam à medida que se aumentam também o número de exemplos processados (SHEN, 2018). Para tal, foram utilizados para o treinamento das redes dados de chuva e de nível do rio das estações telemétricas apresentadas na Figura 2, por contribuírem à variação de nível. De acordo com Veintimilla-Reyes et al. (2016) e Elsafi (2014), a inserção de informações à montante melhora no desempenho das RNA. A fonte dos dados foi o Sistema Nacional de Informações sobre Recursos Hídricos (SNIRH) da Agência Nacional de Águas (ANA), com dados de precipitação obtidos por pluviômetros de báscula e nível de 10 estações da bacia hidrográfica. Dentre as opções disponíveis, escolheu-se esses tipos de dados e essas estações, pois, segundo Gama et al. (2018), existe um número ótimo de informações para o melhor desempenho das redes. O número excessivo pode comprometer esse desempenho.

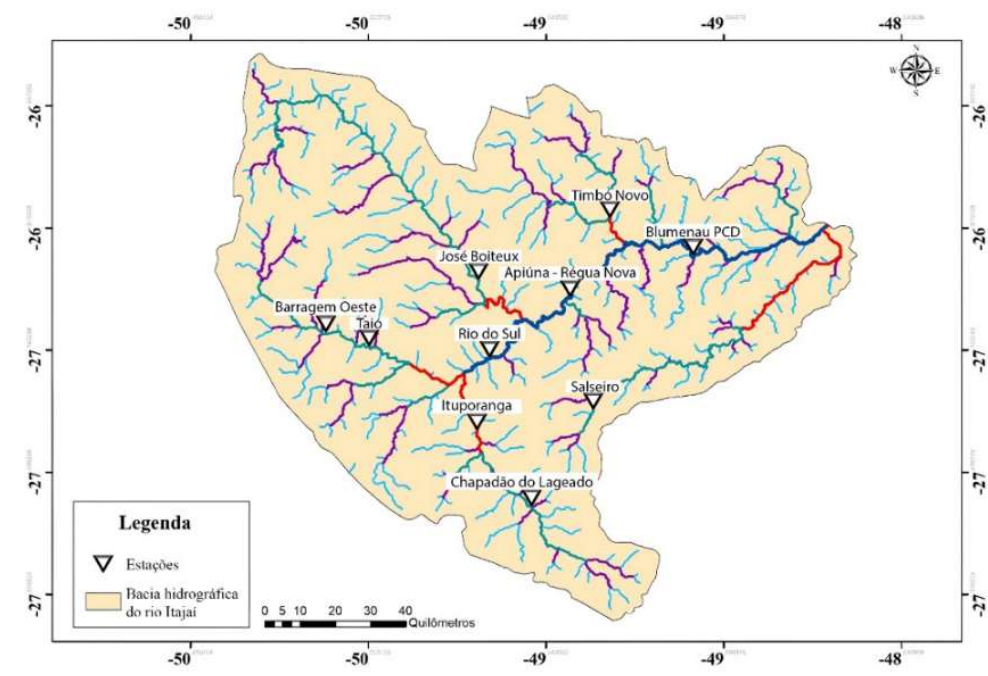

Figura 2: Estações telemétricas da bacia hidrográfica utilizadas como fonte de dados.

Os dados pluviométricos e de nível do rio possuem frequência de $15 \mathrm{~min}$. Foram selecionados 7 eventos hidrológicos de alerta registrados pela estação limnimétrica instalada no município de Blumenau (Tabela 1). $O$ evento 7 apresentou maior completude e consistência de dados e foi, por esse motivo, escolhido como o principal período de teste. Os demais eventos foram utilizados para outros testes.

Tabela 1: Eventos hidrológicos de alerta selecionados.

\begin{tabular}{lll}
\hline Eventos & Datas de início & Datas de término \\
\hline 1 & $28 / 09 / 2009$ & $30 / 09 / 2009$ \\
2 & $01 / 09 / 2011$ & $16 / 09 / 2011$ \\
3 & $08 / 09 / 2013$ & $10 / 10 / 2013$ \\
4 & $04 / 06 / 2014$ & $24 / 06 / 2014$ \\
5 & $07 / 10 / 2015$ & $06 / 11 / 2015$ \\
6 & $18 / 05 / 2017$ & $23 / 06 / 2017$ \\
7 & $27 / 05 / 2019$ & $10 / 06 / 2019$ \\
\hline
\end{tabular}

Os dados foram coletados e reunidos de acordo com sua localização e tipo, e foram escalados à 
mesma unidade de medida: $\mathrm{cm}$ para níveis e $\mathrm{mm}$ para dados de precipitação. A Tabela 2: Coeficiente de correlação de Pearson $(r$ ) entre o nível do rio em Blumenau e em outras estações. apresenta os coeficientes de correlação de Pearson $(r)$ calculados para avaliar o grau de relação linear entre o nível do rio em Blumenau e em outras estações.

Tabela 2: Coeficiente de correlação de Pearson $(r)$ entre o nível do rio em Blumenau e em outras estações.

\begin{tabular}{ll}
\hline Estações & Coeficientes de correlação de Pearson $(r)$ \\
\hline Apiúna - Régua Nova & 0,94 \\
Rio do Sul & 0,91 \\
José Boiteux & 0,82 \\
Barragem Oeste & 0,89 \\
Ituporanga & 0,74 \\
Salseiro & 0,73 \\
Timbó Novo & 0,72 \\
Chapadão do Lajeado & 0,61 \\
Taió & 0,41 \\
\hline
\end{tabular}

\section{Tratamento de dados}

Uma vez obtidos os dados de monitoramento e feita a seleção dos eventos, eles foram submetidos a tratamento e pré-processamento. Paralelamente, realizou-se uma revisão teórica para escolha e confecção das RNA. Optou-se pelas redes Long Short-Term Memory (LSTM) e Multi Layer Perceptron (MLP). Realizouse o treinamento e avaliou-se o desempenho. Modelos com resultados insatisfatórios foram alterados e submetidos a novo treinamento em um processo interativo.

Escolheu-se a linguagem Python, linguagem de programação aberta que combina o potencial das linguagens de programação de uso geral com a facilidade de uso de linguagens de script específicas de domínio, ou também chamadas de linguagem de propósito especial. Esta linguagem sido largamente utilizada para aprendizado de máquina e ciência de dados (MÜLLER et al., 2016). O algoritmo de treinamento criado utilizou a biblioteca Keras para confecção das RNA e a biblioteca SciKit-Learn para o préprocessamento do conjunto de dados e para o cálculo dos indicadores de desempenho.

Para a construção do grupo de validação, segmentos da série de dados foram aleatoriamente retirados. O pré-processamento dos dados se deu pela normalização das séries de forma individual para os dados de cada atributo do conjunto de amostras, com o objetivo de escalonar os atributos e padronizar o intervalo de cada série, conforme observado por Géron (2017) e Silva et al. (2010).

Em uma segunda fase do pré-processamento, as séries temporais foram transformadas em tensores para adentrarem à RNA. O processo de treinamento das redes exige tensores completos, portanto tensores com valores inexistentes foram descartados. Essa foi uma das maneiras descritas por Brownlee (2017) para lidar com valores faltantes.

Para o treinamento das RNA, utilizou-se as configurações originais de suas arquiteturas, sendo alteradas apenas parâmetros principais. Para essa etapa, utilizou-se um computador composto por Processador CPU Intel Core i7-4510 2.0Ghz e 2.6Ghz, GPU Nvidia GeForce 840m e 12 GB de memória RAM. O tempo de treinamento variou de $157 \mathrm{~s}$ a $837 \mathrm{~min}$, de acordo com a configuração da rede. O tempo médio de treinamento do modelo, de acordo com a configurações finais deste trabalho, foi de 12,5 min. 
O hiperparâmetro n_steps representa o número de observações anteriores necessárias para a realização das predições. Dado que os efeitos das variáveis hidrológicas predecessoras no tempo t são observados antes de $\mathrm{t}+32 \mathrm{~h}$ em Blumenau e dada a frequência de dados utilizada neste estudo (15 min), 32 h são representadas por 128 n_steps.

Realizou-se testes com diferentes valores de drop-out para cada tipo de RNA, isto é, desligamento randomizado de neurônios. Essa estratégia de regularização não exige mudança na função de custo e tem sido usada para aumentar a redundância nos arranjos sinápticos. Verificou-se graficamente o número de épocas para convergência entre as funções de treino e validação e número de neurônios necessários. Foi verificado também o aprofundamento da rede por meio da sobreposição de camadas LSTM para verificação da relação entre profundidade e desempenho.

As RNA foram aplicadas ao evento de teste e os resultados foram submetidos ao processo inverso da normalização para retornarem à escala real. O tempo médio de predição foi de, aproximadamente, 4 s. Definidas as melhores configuração para as redes (drop-out, número de épocas, neurônios e camadas), testou-se os modelos LSTM baseado em nível e em nível e chuva para definir qual dessas combinações de variáveis proveria o melhor resultado. Testou-se também uma RNA profunda não recorrente, a MLP e, por fim, verificou-se os resultados do modelo LSTM à diferentes horizontes de previsão.

\section{Avaliação do desempenho}

Para avaliação de desempenho do modelo baseado nas RNA, utilizou-se os seguintes parâmetros: coeficiente de determinação $\left(R^{2}\right)$, o Coeficiente de Eficiência de Nash-Sutcliffe (NSE), a Raiz do Erro Quadrático Médio (RMSE), Erro Quadrático Médio (MSE), o Erro Médio Absoluto (MAE) e a Média Percentual Absoluta do Erro (MAPE).

\section{RESULTADOS E DISCUSSÃO}

\section{Drop-out}

Os parâmetros de avaliação de desempenho dos modelos LSTM e MLP para diferentes valores de drop-out são apresentados na Tabela 3. Observou-se um impacto diferente do drop-out para cada tipo de RNA. Para as redes MLP, foi evidenciado um ganho proporcional ao aumento deste parâmetro enquanto para as LSTM, notou-se um prejuízo. Descartou-se, portanto, essa regularização para as redes LSTM e manteve-se para todas as MLP com valor de 0,5.

Tabela 3: Parâmetros de avaliação de desempenho dos modelos para diferentes valores de drop-out.

\begin{tabular}{llll}
\hline \multirow{2}{*}{ Drop-out } & Parâmetros & Modelos & MLP \\
\cline { 3 - 4 } & & LSTM & 0,97597 \\
& $\mathrm{R}^{2}$ & 0,989206 & 0,967473 \\
& NSE & 0,988262 & 25,14 \\
0,0 & RMSE (cm) & 15,10 & 632,12 \\
& MSE (cm) & 228,12 & 20,91 \\
& MAE (cm) & 11,38 & 6,08 \\
& MAPE (\%) & 3,59 & 0,000373 \\
\hline
\end{tabular}




\begin{tabular}{|c|c|c|c|}
\hline \multirow{7}{*}{0,1} & $\mathrm{R}^{2}$ & 0,986649 & 0,972902 \\
\hline & NSE & 0,986578 & 0,976646 \\
\hline & RMSE (cm) & 16,15 & 21,30 \\
\hline & MSE (cm) & 260,83 & 453,86 \\
\hline & MAE (cm) & 11,05 & 13,44 \\
\hline & MAPE (\%) & 3,49 & 3,61 \\
\hline & MSE val. & 0,000154 & 0,000268 \\
\hline \multirow{7}{*}{0,2} & $\mathrm{R}^{2}$ & 0,973123 & 0,97679 \\
\hline & NSE & 0,973123 & 0,97679 \\
\hline & RMSE $(\mathrm{cm})$ & 22,92 & 28,95 \\
\hline & MSE (cm) & 525,16 & 838,31 \\
\hline & MAE $(\mathrm{cm})$ & 14,98 & 20,21 \\
\hline & MAPE (\%) & 4,33 & 5,76 \\
\hline & MSE val. & 0,000310 & 0,000495 \\
\hline \multirow{7}{*}{0,5} & $\mathrm{R}^{2}$ & 0,973949 & 0,983963 \\
\hline & NSE & 0,812541 & 0,983732 \\
\hline & RMSE (cm) & 60,36 & 17,78 \\
\hline & MSE (cm) & 3643,06 & 316,14 \\
\hline & $\operatorname{MAE}(\mathrm{cm})$ & 48,17 & 11,97 \\
\hline & MAPE (\%) & 12,37 & 3,69 \\
\hline & MSE val. & 0,002149 & 0,000186 \\
\hline
\end{tabular}

\section{Número de épocas e neurônios}

Por meio de testagem, verificou-se tendência de convergência em 40 épocas onde, mesmo após 2.000 interações, o decréscimo do erro foi desconsiderável $(<0,01 \%)$. A Figura 3 apresenta a trajetória de queda do erro até a convergência. Foram testadas também diferentes quantidades de neurônios. Valores acima de 32 neurônios não trouxeram melhoras aos resultados. Este valor foi então fixado.

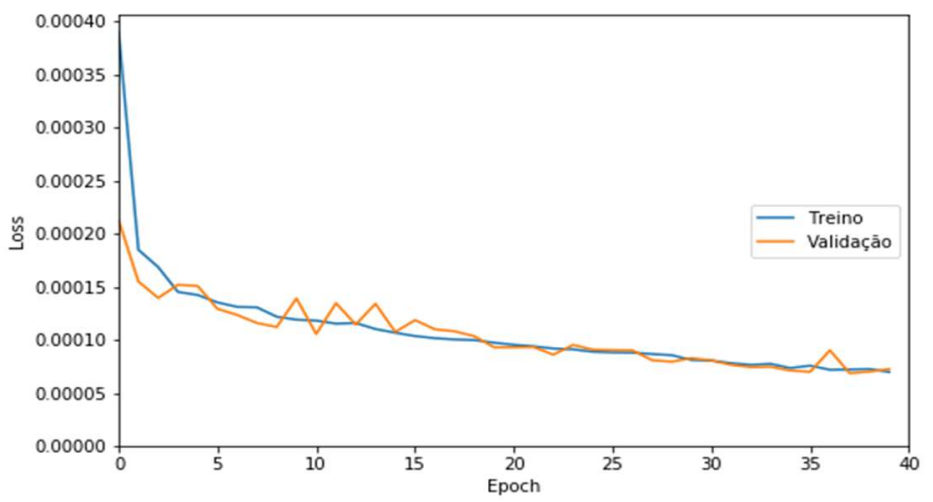

Figura 3: Curva da relação de erro e número de épocas.

\section{Número de camadas LSTM}

De acordo com Haykin (2001), o aprofundamento da rede intensifica sua capacidade de relação não linear. O resultado do aprofundamento da RNA é apresentado na Tabela 4. Valores superiores a 2 camadas não provocaram melhora nos parâmetros. Foi definido, portanto, esse número de camadas para o estudo.

Tabela 4: Parâmetros de avaliação de desempenho dos modelos em relação ao número de camadas.

\begin{tabular}{llll}
\hline \multirow{2}{*}{ Parâmetros } & \multicolumn{2}{l}{ Números de camadas } & $\mathbf{3}$ \\
\cline { 2 - 4 } & $\mathbf{1}$ & $\mathbf{2}$ & 0,976343 \\
\hline $\mathrm{R}^{2}$ & 0,977590 & 0,978961 & 0,966226 \\
NSE & 0,977155 & 0,978683 & 35,61 \\
RMSE $(\mathrm{cm})$ & 29,29 & 28,29 & 1268,25 \\
MSE (cm) & 857,85 & 800,48 & 25,09 \\
MAE (cm) & 17,36 & 16,48 & 6,68
\end{tabular}




\section{Definição do modelo LSTM}

Os modelos LSTM baseado em nível e em nível e chuva foram aplicados à diferentes horizontes de previsão. Os parâmetros de avaliação de desempenho dos modelos são apresentados na Tabela 5.

Tabela 5: Parâmetros de avaliação de desempenho dos modelos LSTM para diferentes horizontes de previsão.

\begin{tabular}{|c|c|c|c|c|c|c|c|c|}
\hline \multirow{2}{*}{ Parâmetros } & \multirow{2}{*}{ Variáveis de entrada } & \multicolumn{7}{|c|}{ Horizontes de previsão (h) } \\
\hline & & 4 & 6 & 8 & 10 & 12 & 14 & 16 \\
\hline \multirow{2}{*}{$R^{2}$} & Nível & 0,998606 & 0,996319 & 0,990809 & 0,979202 & 0,950318 & 0,940898 & 0,946759 \\
\hline & Nível e chuva & 0,998760 & 0,997158 & 0,994119 & 0,982072 & 0,964793 & 0,946290 & 0,927788 \\
\hline \multirow{2}{*}{ NSE } & Nível & 0,998571 & 0,996311 & 0,991406 & 0,981580 & 0,954293 & 0,946007 & 0,927218 \\
\hline & Nível e chuva & 0,998682 & 0,996777 & 0,992009 & 0,982066 & 0,963939 & 0,931765 & 0,899590 \\
\hline \multirow{2}{*}{ RMSE $(\mathrm{cm})$} & Nível & 5,77 & 9,32 & 14,89 & 18,38 & 25,56 & 35,54 & 44,78 \\
\hline & Nível e chuva & 5,46 & 8,51 & 17,63 & 20,14 & 28,24 & 37,55 & 46,85 \\
\hline \multirow{2}{*}{ MSE $(\mathrm{cm})$} & Nível & 33,24 & 86,95 & 221,77 & 337,74 & 653,55 & 1262,96 & 2005,68 \\
\hline & Nível e chuva & 29,80 & 72,37 & 310,82 & 405,63 & 797,78 & 1409,66 & 2194,54 \\
\hline \multirow{2}{*}{$\operatorname{MAE}(\mathrm{cm})$} & Nível & 4,14 & 6,43 & 9,02 & 13,67 & 19,18 & 21,65 & 25,5 \\
\hline & Nível e chuva & 4,01 & 6,08 & 12,00 & 14,38 & 16,62 & 21,8 & 26,99 \\
\hline \multirow{2}{*}{ MAPE (\%) } & Nível & 1,90 & 2,68 & 3,41 & 4,59 & 6,15 & 6,92 & 8,00 \\
\hline & Nível e chuva & 1,50 & 2,50 & 4,49 & 5,01 & 5,31 & 7,31 & 8,5 \\
\hline \multirow{2}{*}{ MSE val. } & Nível & 0,000020 & 0,000051 & 0,000131 & 0,000255 & 0,000494 & 0,000745 & 0,001245 \\
\hline & Nível e chuva & 0,000018 & 0,000043 & 0,000183 & 0,000263 & 0,000471 & 0,000793 & 0,001295 \\
\hline
\end{tabular}

Nota-se grande semelhança entre os parâmetros dos modelos que utilizaram apenas o nível como variável de entrada e aqueles que utilizaram nível e chuva, independente dos horizontes de previsão. Seja pelo número limitado de estações ou pela qualidade dos dados de precipitação, a utilização de dados de chuva observada não proporcionou substancial melhoria de desempenho dos modelos. Observa-se que os modelos apresentaram $\mathrm{R}^{2}$ e NSE acima de 0,99 para horizontes de até $8 \mathrm{~h}$, bom desempenho frente a necessidade de grande acurácia dos modelos preditivos aplicados à problemática das enchentes.

\section{Modelos LSTM e MLP}

Em consonância com o que foi obtido por Hu et al. (2018), em todas as simulações realizadas neste estudo o modelo LSTM apresentou melhor desempenho, se comparado aos resultados do modelo MLP. Além da constatação feita com os parâmetros de avaliação (Tabela 6), esse resultado foi também evidenciado graficamente em diversos experimentos. A Figura 4, por exemplo, apresenta a simulação dos níveis do rio gerada para o evento 7 pelos modelos LSTM e MLP.

Tabela 6: Parâmetros de avaliação de desempenho dos modelos para o evento 7.

\begin{tabular}{lll}
\hline \multirow{2}{*}{ Parâmetro } & Modelo & MLP \\
\cline { 2 - 3 } & LSTM & 0,967837 \\
R ${ }^{2}$ & 0,996319 & 0,966746 \\
RMSE $(\mathrm{cm})$ & 0,996311 & 25,42 \\
MSE (cm) & 9,44 & 646,25 \\
MAE (cm) & 86,47 & 18,28 \\
MAPE (\%) & 6,22 & 5,11 \\
MSE val. & 3,21 & 0,000381 \\
\hline
\end{tabular}

Nota-se, através de gráficos de dispersão dos níveis observados e calculados apresentados na Figura 
5, boa relação para diferentes horizontes de previsão. Conforme esperado, observa-se maior dispersão à medida que se aumenta a antecedência da previsão.

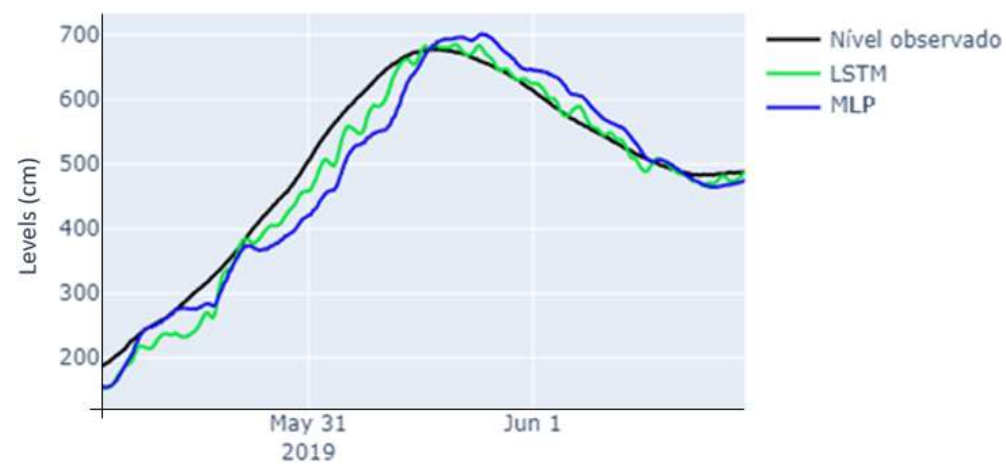

Figura 4: Simulação dos níveis do rio para o evento 7.
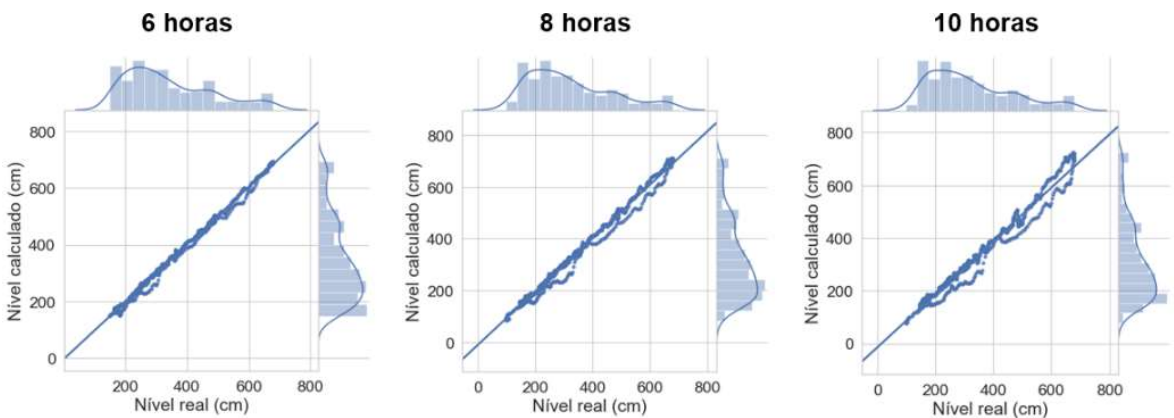

Figura 5: Gráficos de dispersão dos níveis do rio observados e calculados pelos modelos LSTM para o evento 7.

Mesmo com excelente resultado nos parâmetros de avaliação, com valores de $\mathrm{R}^{2}$ e NSE acima de 0,98, pode-se notar resíduos máximos de até $60 \mathrm{~cm}$ em determinados períodos do evento para previsão com 8 horas de antecedência. Aplicou-se o modelo LSTM baseado em nível ao evento 6 com antecedência ajustada para 6 e 8 h e a Tabela 7 apresenta os parâmetros de avaliação dessa aplicação.

Tabela 7: Parâmetros de avaliação de desempenho do modelo LSTM para diferentes horizontes de previsão para o evento 6 .

\begin{tabular}{lll}
\hline \multirow{2}{*}{ Parâmetros } & \multicolumn{2}{l}{ Horizontes de previsão $(\mathbf{h})$} \\
\cline { 2 - 3 } & $\mathbf{6}$ & $\mathbf{8}$ \\
\hline $\mathrm{R}^{2}$ & 0,996594 & 0,990551 \\
NSE & 0,995548 & 0,989224 \\
RMSE $(\mathrm{cm})$ & 7,72 & 21,01 \\
MSE $(\mathrm{cm})$ & 59,65 & 441,35 \\
MAE (cm) & 4,82 & 10,84 \\
MAPE (\%) & 1,89 & 3,40 \\
MSE val. & 0,000035 & 0,000260 \\
\hline
\end{tabular}

A Figura 6 apresenta as simulações geradas neste ensaio. Observa-se boa aderência ao observado em ambas as previsões, especialmente à de menor horizonte, conforme esperado. Panda et al. (2010) apresentaram NSE de 0,8419 utilizando modelo baseado em RNA. A diferença entre os níveis observados e simulados obtidos a partir desse modelo foi considerada muito menor do que a diferença com os níveis simulados por um modelo hidrodinâmico fisicamente embasado.

Gama et al. (2018) obtiveram como maiores valores de NSE 0,980 e 0,927 para previsões com horizontes de 5 e 12 h, respectivamente. Em conformidade com o que foi apresentado neste estudo, Gama et al. (2018) e Finck (2020), por exemplo, também apresentaram maiores valores de NSE para menores 
horizontes de previsão de níveis fluviais por RNA. Pedrollo (2017) comprovou ser possível com RNA efetuar previsões de níveis com qualidade com horizontes de previsão entre 5 e de $11 \mathrm{~h}$, horizontes semelhantes aos do presente estudo. O mesmo foi observado por Soares et al. (2015a; 2015b), que obtiveram bons resultados com um modelo de previsão de cheias com $6 \mathrm{~h}$ de antecedência.

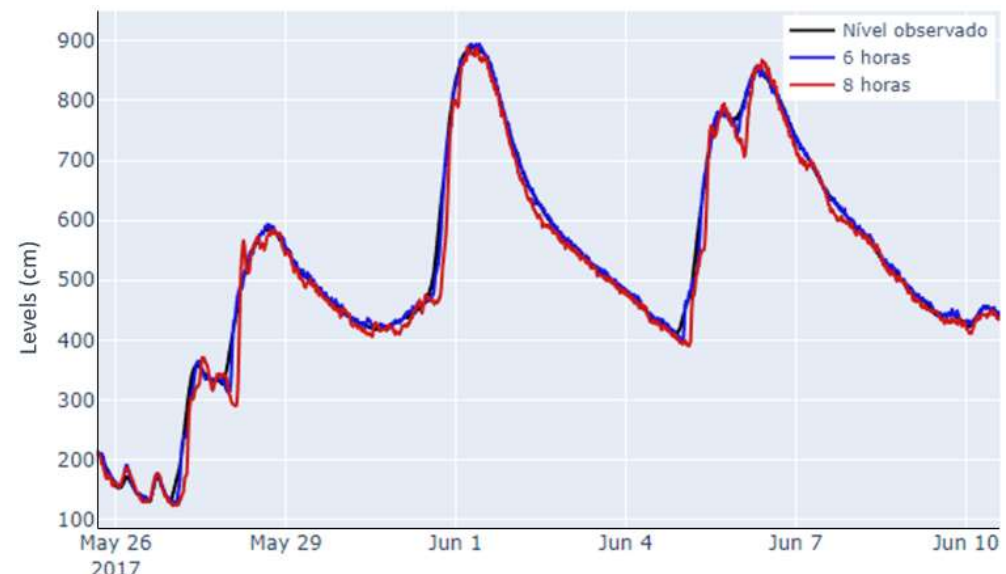

Figura 6: Simulação gerada pelo modelo LSTM para diferentes horizontes de previsão para o evento 6.

\section{CONCLUSÕES}

O estudo evidenciou a viabilidade do uso de RNA como solução preditiva para eventos de enchente, demonstrando relevante desempenho. A configuração de rede que trouxe os melhores resultados contou com arquitetura LSTM de dupla camada, 32 neurônios e convergência satisfatória em 40 épocas.

O estudo evidenciou que o modelo LSTM, com simples pré-processamento, é capaz de prever o nível d'água do rio Itajaí-Açu durante eventos extremos de cheia, com alta precisão, apresentando resultados melhores em comparação com o modelo não recorrente MLP.

Este estudo apresenta uma proposta de solução de modelo de previsão de níveis viável, passível de aplicação como ferramenta de previsão em tempo real para a área de estudo. Este trabalho contribui para o desenvolvimento de sistemas de apoio à gestão de recursos hídricos e para mitigação dos impactos provocados por desastres, abrangendo os âmbitos social, econômico e ambiental.

Para estudos futuros, sugere-se aplicação de RNA com arquiteturas mais complexas, além da testagem de métodos de preenchimento de dados, como interpolações, para avaliação do impacto destes no desempenho das previsões. Pode-se, ainda, ser estudada a confiabilidade estatística dos modelos baseados em RNA profundas, comparando-os aos métodos autorregressivos.

AGRADECIMENTOS: O presente trabalho foi realizado com apoio da Coordenação de Aperfeiçoamento de Pessoal de Nível Superior (CAPES) - Brasil (Código de Financiamento 001 e Processo 88881.143991/2017-01). O autor agradece à CAPES pela concessão da bolsa de mestrado.

\section{REFERÊNCIAS}

ANA. Agência Nacional de Águas. Sistema HIDRO de telemetria da Rede Hidrometeorológica Nacional do Brasil. Brasília: ANA, 2015.
BROWNLEE, J.. How to Handle Missing Timesteps in Sequence Prediction Problems with Python. Melbourne: Machine Learning Mastery, 2017. 
CASTRO, A. L. C.. Manual de Desastres. Brasília: Ministério da Integração Nacional, Secretaria Nacional de Defesa Civil, 2003.

CEPED; UFSC. Centro Universitário de Estudos e Pesquisas Sobre Desastres; Universidade Federal de Santa Catarina. Atlas Brasileiro de Desastres Naturais: 1991 a 2012. Florianópolis: CEPED, 2013.

CORDERO, A.; SALVADOR, D.; REFOSCO, J.; TACHINI, M.. Cotas-Enchente do município de Blumenau. In: SIMPÓSIO BRASILEIRO DE RECURSOS HÍDRICOS, 20. Anais. Bento Gonçalves, 2013.

CRUZ, M. F. M.; RODRIGUES, L. D.; VERSIANI, B. R.. Previsão de Vazões com a Metodologia DPFT e com Redes Neurais Artificiais. Revista Brasileira de Recursos Hídricos, Porto Alegre, v.15, n.1, p.121-132, 2010. DOI: https://doi.org/10.21168/rbrh.v15n1.p121-132

ELSAFI, S. H.. Artificial Neural Networks (ANNs) for flood forecasting at Dongola Station in the River Nile, Sudan. Alexandria Engineering Journal, v.63, p.655-662, 2014. DOI: https://doi.org/10.1016/j.aej.2014.06.010

FINCK, J. S.. Previsão em tempo atual de níveis fluviais com redes neurais artificiais: Aplicação à bacia do rio TaquariAntas/RS. Dissertação (Mestrado em Recursos Hídricos e Saneamento Ambiental) - Universidade Federal do Rio Grande do Sul, Porto Alegre, 2020.

GAMA, C. H. A.; PEDROLLO, O. C.. Previsão de níveis na bacia do rio Mundaú a partir de redes neurais artificiais. In: SIMPÓSIO DE RECURSOS HÍDRICOS DO NORDESTE, 14. Anais. Maceió, 2018.

GERBER, D.; PERTILLE, C. T.; VIEIRA, F. S.; CORRÊA, B. J. S.; SOUZA, C. F.. Caracterização morfométrica da Bacia Hidrográfica do Rio Itajaí-Santa Catarina. Acta Biológica Catarinense, Joinville, v.5, n.1, p.72-83, 2018. DOI: http://doi.org/10.21726/abc.v5i1.446

GÉRON, A.. Hands-On Machine Learning with Scikit-Learn and TensorFlow: Concepts, Tools, and Techniques to Build Intelligent Systems. Sebastopol: O’Reilly, 2017.

GOTARDO, R.; PIAZZA, G. A.; TORRES, E.; SEVERO, D. L.; KAUFMANN, V.. Distribuição espacial e temporal das chuvas no estado de Santa Catarina. Geosul, Florianópolis, v.33, n.67, p.253-276, 2018. DOI: https://doi.org/10.5007/21775230.2018v33n67p253

HAYKIN, S.. Redes Neurais: princípios e prática. Porto Alegre: Bookman, 2001.

HU, C.; WU, Q.; LI, H.; JIAN, S.; LI, N.; LOU, H.. Deep learning with a long short-term memory networks approach for rainfall-runoff simulation. Water, v.10, n.11, p.1543, 2018. DOI: https://doi.org/10.3390/w10111543

JHA, A. K., BLOCH, R., LAMOND, J.. Cidades e inundações: um guia para a gestão integrada de risco de inundação urbana para o século XXI. Washington, 2012.

KRON, W.. Flood risk = hazard $\mathrm{x}$ values $\mathrm{x}$ vulnerability. Water International, v.30, n.1, p.58-68, 2005.

LIANG, C.; LI, H.; LEI, M.; DU, A.. Dongting lake water level forecast and its relationship with the three gorges dam based on a long short-term memory network. Water, v.10, n.10, p.1389, 2018. DOI: https://doi.org/10.3390/w10101389

MOSAVI, A.; OZTURK, P.; CHAU, K.. Flood prediction using machine learning models: Literature review. Water, v.10, n.11, p.1536, 2018. DOI: https://doi.org/10.3390/w10111536

MÜLLER, A. C.; GUIDO, S.. Introduction to machine learning with Python: a guide for data scientists. O'Reilly, 2016.

PANDA, R. K.; PRAMANIK, M.. Simulation of river stage using artificial neural network and MIKE 11 hydrodynamic model. Computers \& Geosciences, v.36, p.735-745, 2010. DOI: https://doi.org/10.1016/i.cageo.2009.07.012

PEDROLLO, O. C.. Previsão de curto prazo de níveis com redes neurais artificiais para a cidade de Estrela (RS): resultados preliminares. In: SIMPÓSIO BRASILEIRO DE RECURSOS HÍDRICOS, 22. Anais. Florianópolis, 2017.

SCHETTINI, C. A. F.. Caracterização física do estuário do Rio Itajaí-Açu, SC. Revista Brasileira de Recursos Hídricos, Porto Alegre, v.7, n.1, p.123-142, 2002. DOI: http://doi.org/10.21168/rbrh.v7n1.p123-142

SHEN, C.. A transdisciplinary review of deep learning research and its relevance for water resources scientists. Water Resources Research, v.54, n.11, p.8558-8593, 2018. DOI: https://doi.org/10.1029/2018WR022643

SILVA, I. N.; SPATTI, H. D.; FLAUZINO, R. A.. Redes Neurais Artificiais: para engenharia e ciências aplicadas. São Paulo: Artliber, 2010

SOARES, D. G.; TEIVE, R. C. G.. Estudo Comparativo entre as Redes Neurais Artificiais MLP e RBF para Previsão de Cheias em Curto Prazo. Revista de Informática Teórica e Aplicada, v.22, n.2, p.67-86, 2015a. DOI: https://doi.org/10.22456/2175-2745.53236

SOARES, D. G.; TEIVE, R. C. G.. Previsão de cheias do Rio Itajaí-Açu utilizando redes neurais artificiais. In: COMPUTER ON THE BEACH Anais. Itajaí, 2015b. DOI: https://doi.org/10.14210/cotb.v0n0.p308\%20-\%20317

UN OCHA. The United Nations Office for the Coordination of Humanitarian Affairs. Health Emergency and Disaster Risk Management Framework. Geneva: World Health Organization, 2019.

VEINTIMILLA-REYS, J.; CISNEROS, F.; VANEGAS, P.. Artificial Neural Networks applied to flow prediction: A use case for the Tomebamba river. Procedia Engineering, v.162, p.153161, 2016. DOI: https://doi.org/10.1016/j.proeng.2016.11.031

VILLELA, S. M.; MATTOS, A.. Hidrologia Aplicada. São Paulo McGraw-Hill do Brasil, 1975.

ZHANG, J.; ZHU, Y.; ZHANG, X.; YE, M.; YANG, J.. Developing a Long Short-Term Memory (LSTM) based model for predicting water table depth in agricultural areas. Journal of hydrology, v.561, p.918-929, 2018. DOI: https://doi.org/10.1016/j.jhydrol.2018.04.065

A CBPC - Companhia Brasileira de Produção Científica (CNPJ: 11.221.422/0001-03) detém os direitos materiais desta publicação. Os direitos referem-se à publicação do trabalho em qualquer parte do mundo, incluindo os direitos às renovações, expansões e disseminações da contribuição, bem como outros direitos subsidiários. Todos os trabalhos publicados eletronicamente poderão posteriormente ser publicados em coletâneas impressas sob coordenação da Sustenere Publishing, da Companhia Brasileira de Produção Científica e seus parceiros autorizados. Os (as) autores (as) preservam os direitos autorais, mas não têm permissão para a publicação da contribuição em outro meio, impresso ou digital, em português ou em tradução. 